\title{
Clinical Longevity of Indirect Composite Resin Inlays and Onlays: An Up to 9-Year Prospective Study
}

\author{
Aristidis Galiatsatos ${ }^{1, \odot}$ Panagiotis Galiatsatos ${ }^{2}$ Dimitra Bergou ${ }^{3}$ \\ ${ }^{1}$ Division of Dental Technology, Department of Biomedical \\ Sciences, University of West Attica, Athens, Greece \\ 2School of Dentistry, National and Kapodistrian University of \\ Address for correspondence Aristidis Galiatsatos, DDS, PhD, \\ Galiatsatos Aristidis, 60 Rogakou Street, 15125 Athens, Greece \\ (e-mail: agal@uniwa.gr). \\ Athens, Athens, Greece \\ 3 Private Practice, Athens, Greece \\ Eur J Dent 2022;16:202-208.
}

\author{
Abstract \\ Keywords \\ - adhesion \\ - clinical longevity \\ - esthetics \\ - indirect composite \\ - inlay \\ - marginal discoloration \\ - onlay \\ - restorative dentistry
}

Objective This clinical study evaluated the clinical performance of composite resin inlays and onlays over 9 years.

Materials and Methods Sixty composite resin inlays and onlays were placed in 32 patients, aged 20 to 60 years, by a single operator using the same clinical procedure. The restorations were examined for fracture rate; esthetics; and patient acceptance and marginal integrity, including caries, marginal discoloration, tooth integrity, and surface texture. All restorations were evaluated at the time of placement and 3, 6, and 9 years after placement by using the modified U.S. Public Health Service criteria. Results At the 3-year follow-up, an Alpha score was given to $88.4 \%$ of restorations, while a Bravo score was given to the remaining $11.6 \%$. There was not any failure. At the 6 -year follow-up, the success rate of the restorations was $100 \%$ without failure. None of the restorations was scored with Delta (D). An Alpha score was given to $60 \%$ of the restorations, a Bravo score was assigned to $35 \%$, and a Charlie score was $5 \%$ of the restorations. Overall, the success rate of the restorations at 9-year follow-up was $85 \%$ and the failure rate was $15 \%$. An Alpha score was given to $15 \%$ of the restorations, a Bravo score was given to $50 \%$, a Charlie score was assigned to $20 \%$, and a D score was given to $15 \%$ of the restorations.

Conclusion Indirect resin composite inlays and onlays showed acceptable long-term clinical results. The success rate of the restorations at 9 -year follow-up was $85 \%$ and the failure rate was $15 \%$.

\section{Introduction}

The quest for an esthetic posterior restoration that is both conservative and predictable has plagued the dental profession for many years. Under this theory, indirect inlays and onlays have been used increasingly in the last decades.

In today's dental practice, there are many materials and solutions available to restore a partially damaged posterior tooth. The development of reinforcing ceramic systems, coupled with the ability to etch and bond the porcelain to the underlying etched tooth structure, has allowed these types of restoration to become a part of today's operative armamentarium. Many clinical studies examined the performance of ceramic inlays and onlays for varying serving times with very good results. Unfortunately, ceramics have some disadvantages, such as low tensile strength, excessive brittleness, fracture, and time-consuming laboratory procedures. $^{1-4}$ published online November 8, 2021
DOI https://doi.org/

$10.1055 / \mathrm{s}-0041-1735420$ ISSN 1305-7456

\section{(c) 2021. The Author(s).}

This is an open access article published by Thieme under the terms of the Creative Commons Attribution License, permitting unrestricted use, distribution, and reproduction so long as the original work is properly cited. (https://creativecommons. org/licenses/by/4.0/)

Thieme Medical and Scientific Publishers Pvt. Ltd. A-12, 2nd Floor, Sector 2, Noida-201301 UP, India 
In response to the limitations of ceramics, new polymer-based resin-composite materials have been developed. This new category of materials referred to as hybrid polymers or hybrid ceramics, also known as resin-matrix-ceramics, resin-based ceramics, or nanoceramics represents the synergy of ceramics and composites with their respective beneficial mechanical properties. Some of them are normally stress distribution; reduced polymerization shrinkage; very good wear resistance; and excellent characterization and adjustment of the occlusal surface, reparability, and easy manipulation compared with ceramic. $^{5-13}$ Furthermore, it appears that these materials meet the increasing demands of the patients for an esthetic appearance of the posterior teeth. Today, there are many new polymeric restorative materials for indirect applications ( - Table 1) . $^{8-11}$

Searching the bibliographical sources, the number of long-term clinical studies regarding the performance of these materials is limited. So, the purpose of this clinical study was to evaluate the clinical performance of composite inlays and onlays longitudinally over 9 years.

\section{Materials and Methods}

This clinical survey involved 32 patients, the age and gender of which are shown in - Table 2 . The 32 patients required aesthetic and functional treatment in their posterior teeth due to dental caries, recurrent caries, or replacement of old amalgam fillings. They received 60 inlays and onlays in a private dental office in Athens. All of the treated teeth were vital. All patients accepted their participation in the research protocol and agreed to a recall program for 9 years, consisting of one appointment every 3 years. This survey excluded patients with a high index of caries, poor level of oral hygiene, malfunctions (impacted and/or misaligned teeth, malocclusion), active periodontal or/and pulpal disease, and parafunctional habits like bruxism. None of the patients dropped out or were dismissed. - Table 3 shows the

Table 1 Modern polymeric systems for indirect restorations

\begin{tabular}{|l|l|}
\hline Material & Manufacturer \\
\hline Artglass & Heraeus/Kulzer \\
\hline Signum & Heraeus/Kulzer \\
\hline Sinfony & $3 \mathrm{M}$ - ESPE \\
\hline Ceramage & Shofu \\
\hline Solidex & Shofu \\
\hline Gradia Indirect, Plus & GC Corp \\
\hline Targis & Ivoclar-Vivadent \\
\hline SR Adoro & Ivoclar-Vivadent \\
\hline SR Nexco & Ivoclar-Vivadent \\
\hline Belleglass & Kerr \\
\hline Estenia & Kuraray \\
\hline Premise indirect & Kerr \\
\hline Sculpture & Jeneric/Pentron \\
\hline
\end{tabular}

distribution of the teeth receiving indirect restorations. The restorations included 18 one-surface inlays, 20 two-surfaces inlays, 10 three-surfaces inlays, and 12 onlays.

All clinical procedures were performed by one clinician, and all materials were used according to the recommendations of the manufactures.

For the tooth preparations, the basic principles for adhesive restorations were followed.

The cavity form was developed as conservatively as possible; only the compromised portion of the tooth was removed and convenient access was provided for the subsequent restoration. The axial walls of the cavity preparation were prepared with a 6 - to 10 -degree taper by using appropriate diamond burs (Inlay Prep-set, Intensive, Viganello-Lugano, Switzerland), which allows easier placement and removal of the restoration during the try-in phase. For the onlay preparation, a 1.5 - to $2.0-\mathrm{mm}$ reduction in vertical height of the cusp and all occluding areas and rounded occlusal-axial angles, and hollow-ground chamfer finish line was necessary. Special diamond burs were used for tooth preparation. (Inlay Prep-set, Intensive, Viganello-Lugano, Switzerland). Where necessary, a glass-ionomer base in thickness greater than $1.5 \mathrm{~mm}$ was placed on the pulpal floor for protection.

The final impression was made with a siloxane material (Speedex, Coltene -Whaledent Co.). An impression of the opposite teeth was made, using an alginate impression material (Cavex impressional, Cavex Co.). Also, an interocclusal record was made (Luxa Bite, DMG Co.). After impression making, the teeth were provisionalized with a light-cured provisional material (Clip Light-Cured Provisional Filling, Voco Co.).

One dental technician made all the restorations using a modern polymeric system (Gradia, GC) according to the manufacturer's instructions.

The bonding procedure for each tooth was conducted under a rubber dam isolation. The cavity preparation was cleaned with a wet slurry of flour pumice and then was treated with a $37 \%$ phosphoric acid gel etchant (Etching gel, DMP Co, Greece). After etching and drying, the dentin adhesive system (Gluma 2 Bond, Kulzer Co, Germany) was applied uniformly and gently air thinned. The restoration was cleaned in the ultrasonic cleaner and then washed and dried. After that, it was coated with a silane coupling agent (Monobond S, Ivoclar, Vivadent). Finally, the restoration was luted adhesively with composite resin cement (Variolink II, Ivoclar, Vivadent). The super floss beneath the contact point was drawn through to remove the excess resin interproximally. The restoration was held firmly in place and was light-cured from all aspects-proximal, facial, lingual, and occlusal-for 60 seconds each. Once the restoration bonded into position and cured completely, the final occlusal adjustment was made. Finally, the finishing procedures were done with a series of microfine diamond strips, multifluted finishing burs, and polishing disks specifically designed for the finishing process (Intensive metal diamond strips, Intensive proxostrip, Composhape set A\&P Intensive, Viganello-Lugano, Switzerland). 
Table 2 Age and gender of patients

\begin{tabular}{|l|l|l|l|}
\hline Age $(y)$ & Men & Women & Total \\
\hline $20-30$ & 3 & 8 & 11 \\
\hline $31-40$ & 5 & 5 & 10 \\
\hline $41-50$ & 3 & 3 & 6 \\
\hline $51-60$ & 3 & 2 & 5 \\
\hline Total & 14 & 18 & 32 \\
\hline
\end{tabular}

Table 3 Distribution of the teeth receiving indirect restorations

\begin{tabular}{|l|l|l|l|}
\hline Tooth & Maxilla & Mandible & Total \\
\hline First premolar & 5 & 12 & 17 \\
\hline $\begin{array}{l}\text { Second } \\
\text { premolar }\end{array}$ & 8 & 10 & 18 \\
\hline First molar & 8 & 9 & 17 \\
\hline Second molar & 3 & 5 & 8 \\
\hline Total & 24 & 36 & 60 \\
\hline
\end{tabular}

Patients were given detailed oral hygiene instructions and asked to inform the clinician of any problem that occurs in the treated teeth.

\section{Evaluation}

Each restoration was evaluated at baseline and 3, 6, and 9 years, with mirror, probe, and a dental loupe $(\times 4.5)$, by another clinician who was not involved in the clinical procedures. The evaluation followed the modified U.S. Public Health Service (USPHS) criteria for the following parameters: surface texture, color match, marginal adaptation, marginal discoloration, restoration integrity (fracture), tooth integrity, sensitivity, and patient satisfaction ( $\mathbf{- T a b l e s} \mathbf{4}$ and $\mathbf{5}$ )$^{4,14-16}$ Descriptive analysis was performed for the evaluation

Table 4 Modified U.S. Public Health Service criteria for evaluation

\begin{tabular}{|l|l|l|}
\hline $\begin{array}{l}\text { Modified } \\
\text { USPHS } \\
\text { criteria }\end{array}$ & Description & Score \\
\hline $\begin{array}{l}\text { Excellent/ } \\
\text { good }\end{array}$ & $\begin{array}{l}\text { Perfect without fault, or slight devia- } \\
\text { tions from ideal performance, correc- } \\
\text { tion possible without damage of tooth } \\
\text { or restoration }\end{array}$ & Alpha \\
\hline Acceptable & $\begin{array}{l}\text { Small defects, every clinical interven- } \\
\text { tion is performed without damaging } \\
\text { the tooth or the restoration and no } \\
\text { negative effect is expected }\end{array}$ & Bravo \\
\hline $\begin{array}{l}\text { Unacceptable } \\
\text { but } \\
\text { repairable }\end{array}$ & $\begin{array}{l}\text { Serious defects, the restoration/tooth } \\
\text { needs to be repaired }\end{array}$ & Charlie \\
\hline Poor/failure & Immediate replacement necessary & Delta \\
\hline
\end{tabular}

Abbreviation: USPHS, U.S. Public Health Service. of the restorations and the tooth outcome according to the modified USPHS criteria.

\section{Results}

A total of 60 inlays and onlays were bonded on posterior teeth in 32 patients. All patients underwent the recall program. Thus, no dropout was experienced at 9 years (100\%).

The results for the evaluated factors at the follow-up periods are given in - Table 6.

At the baseline and the 3-year follow-up, all restorations obtained an Alpha score for the criteria: "restoration integrity" and "tooth integrity."

At the 3-year examination, an Alpha score was given to $88.4 \%$ of restorations, while a Bravo score was given to the remaining $11.6 \%$. There was not any failure.

At the 6-year follow-up, the success rate of the restorations was $100 \%$ without failure. None of the restorations was scored with Delta (D). An Alpha score was given to 60\% of the restorations, a Bravo score was assigned to $35 \%$, and a Charlie score was $5 \%$ of the restorations.

Overall, the success rate of the restorations at 9-year follow-up was $85 \%$ and the failure rate was $15 \%$. An Alpha score was given to $15 \%$ of the restorations, a Bravo score was given to $50 \%$, a Charlie score was assigned to $20 \%$, and a D score was given to $15 \%$ of the restorations. At 9-year examination with D scored: one restoration for the "surface texture," two restorations for the "tooth integrity" (small cusp fracture), and three restorations for "marginal adaptation" and also three restorations for "marginal discoloration."

Of the 60 teeth restored, five of them showed sensitivity in the first week immediately after bonding. This slight sensitivity was resolved by the second week and completely remitted without long-term consequences. There was no additional sensitivity reported in any of the restorations through the 3and 6-year recall. At a 9-year recall, three teeth (molars) had increased cold sensitivity (scored B) and one (premolar) had spontaneous pain referred by the patient (scored C).

Regarding the criterion "patient satisfaction," at the 9-year follow-up, the Alpha score was $81.66 \%$. There was only one patient completely dissatisfied (-Table 6 ).

\section{Discussion}

This study was evaluated the clinical performance of indirect polymer composite (Gradia) inlays and onlays in posterior teeth by using modified USPHS criteria.

In the 1970s, Cvar and Ryge ${ }^{17}$ introduced an intraoral evaluation system, known as the USPHS method, which was used to clinically evaluate resin composite restorations in posterior teeth. Over the years, this method has received many improvements so that it is reliable and valid. Today, many clinical trials use the USPHS criteria to evaluate posterior restorations. ${ }^{4,18-21}$ 
Table 5 Descriptive criteria used for scoring restoration quality

\begin{tabular}{|c|c|c|c|c|}
\hline Parameter & Alpha (A) & Bravo (B) & Charlie (C) & Delta (D) \\
\hline Surface texture & Completely smooth surface & $\begin{array}{l}\text { Slightly rough surface or } \\
\text { with small notches, loss } \\
\text { of gloss }\end{array}$ & $\begin{array}{l}\text { Surface with visual and } \\
\text { tactile roughness with } \\
\text { visual cracks and notches }\end{array}$ & $\begin{array}{l}\text { Visibly damaged sur- } \\
\text { face, pits, and grooves } \\
\text { throughout the material }\end{array}$ \\
\hline Color match & $\begin{array}{l}\text { Corresponding color } \\
\text { between the tooth and the } \\
\text { restoration }\end{array}$ & $\begin{array}{l}\text { Moderate mismatch } \\
\text { in color, shade, or } \\
\text { translucency }\end{array}$ & $\begin{array}{l}\text { Extensive color mis- } \\
\text { match, outside the } \\
\text { limits of acceptable } \\
\text { appearance }\end{array}$ & Gross mismatch \\
\hline Marginal adaptation & $\begin{array}{l}\text { No cracks/gaps are visible } \\
\text { along the margins of the } \\
\text { restoration, the probe does } \\
\text { not catch }\end{array}$ & $\begin{array}{l}\text { The probe slightly } \\
\text { catches along the } \\
\text { margins }\end{array}$ & $\begin{array}{l}\text { Visible cracks/gaps or } \\
\text { extensive probe penetra- } \\
\text { tion between cavity wall } \\
\text { and restoration }\end{array}$ & $\begin{array}{l}\text { The restoration is either } \\
\text { fractured, missing, or } \\
\text { movable }\end{array}$ \\
\hline $\begin{array}{l}\text { Marginal } \\
\text { discoloration }\end{array}$ & $\begin{array}{l}\text { No discoloration or minor } \\
\text { staining can be polished }\end{array}$ & $\begin{array}{l}\text { Moderate surface } \\
\text { staining, not esthetically } \\
\text { unacceptable }\end{array}$ & $\begin{array}{l}\text { Surface staining present } \\
\text { on the restoration, inter- } \\
\text { vention necessary }\end{array}$ & $\begin{array}{l}\text { Severe staining and/or } \\
\text { subsurface staining }\end{array}$ \\
\hline Restoration integrity & $\begin{array}{l}\text { No defects in material, no } \\
\text { cracks, or fractures }\end{array}$ & $\begin{array}{l}\text { Two or more cracks and/ } \\
\text { or chipping, but not } \\
\text { affecting the marginal } \\
\text { integrity or proximal } \\
\text { contact }\end{array}$ & $\begin{array}{l}\text { Chipping fractures that } \\
\text { affect the marginal qual- } \\
\text { ity or proximal contact }\end{array}$ & $\begin{array}{l}\text { Partial or complete loss } \\
\text { of the restoration }\end{array}$ \\
\hline Tooth integrity & No enamel defects/chipping & $\begin{array}{l}\text { Visible enamel cracking, } \\
\text { no exposed dentin }\end{array}$ & $\begin{array}{l}\text { Major enamel crack- } \\
\text { ing with dentin or } \\
\text { base exposed, probe } \\
\text { penetrates }\end{array}$ & Cusp or tooth fracture \\
\hline Sensitivity & $\begin{array}{l}\text { A normal reaction to cold } \\
\text { spray compared with nonre- } \\
\text { stored teeth }\end{array}$ & $\begin{array}{l}\text { Cold sensitivity has } \\
\text { increased }\end{array}$ & $\begin{array}{l}\text { Spontaneous pain } \\
\text { referred by the patient }\end{array}$ & $\begin{array}{l}\text { The tooth does not show } \\
\text { signs of vitality }\end{array}$ \\
\hline Patient satisfaction & Satisfied & $\begin{array}{l}\text { Complained about the } \\
\text { esthetic outcome }\end{array}$ & $\begin{array}{l}\text { Requested an } \\
\text { improvement }\end{array}$ & Completely dissatisfied \\
\hline
\end{tabular}

Ceramic or composite inlays and onlays, also known as "esthetic inlays/onlays," have become viable solutions for partially damaged posterior teeth. These restorations offer many advantages over comparable restorations: they restore strength to compromised teeth, they are more esthetic, and they are highly conservative.

The choice between ceramic or composite as restorative materials has become increasingly complicated since composite materials have improved in their physicomechanical properties, wear resistance, and esthetic potential.

So, this clinical study evaluated the clinical performance of composite resin inlays and onlays made of an improved polymeric material (Gradia, GC) over 9 years.

This polymeric material (Gradia, GC) contains microfine ceramic pre-polymer fillers with urethane dimethacrylate matrix. From many studies, it has been found that this material has very good physicomechanical properties, such as high strength, wear-resistance, and superior polishability for such restorations. ${ }^{10,22,23}$

In this clinical study, at the 3-year and 6-year follow-up, the success rate of the restorations was $100 \%$ without failure. At a 9-year follow-up, the success rate was $85 \%$ and the failure rate was $15 \%$.

It is important to distinguish between early failures (at baseline or after a few weeks/ months), from a medium time frame (3-6 years), and late failures (6-9 years). Up to 6 years, the color match, restoration integrity, tooth integrity, and sensitivity were acceptable and did not show a significant difference. None of the restorations was scored with D.
An Alpha score was given to $60 \%$ of the restorations, a Bravo score was assigned to $35 \%$, and a Charlie score was $5 \%$ of the restorations.

On the other hand, late failures occurred at 9-year follow-up with a total failure rate of $15 \%$. Especially, nine restorations were graded with $\mathrm{D}$, and only one patient was unsatisfied. The main reasons for failures were tooth integrity, surface texture, and marginal discoloration/adaptation.

About tooth integrity, there were only two teeth (one molar and one premolar) that occurred small cusp fracture at 9 years. The teeth had no clinical symptoms, as the restorations remained intact and boned in place and the fractures repaired with composite resin. Although the failure rate was very small, it should be concluded that preparation design has a significant effect on the risk of tooth fracture. Tooth preparation should follow the basic principles for these restorations. Some of them are as follows: (1) enamel should be supported by sound, healthy dentine, (2) well-rounded angles on the cuspal preparation, to prevent the propagation of restoration fracture from these sharp stress point, (3) all axial walls should be prepared with a 6- to 10-degree taper, which allows easier placement and removal of the restoration during the try-in phase, and (4) a 1.5 - to $2.0-\mathrm{mm}$ reduction in vertical height of the cups and all occluding areas.

About the surface texture, there was only one restoration scored with D at the end of the 9-year follow-up. This finding is most likely due to the improved mechanical properties of modern composite materials. The process of laboratory 
Table 6 Frequency distribution of the scores for the evaluated criteria at the follow-up periods

\begin{tabular}{|c|c|c|c|c|}
\hline Category/rating & Baseline $n, \%$ & 3 у $n, \%$ & 6 y $n, \%$ & 9 yn, \% \\
\hline \multicolumn{5}{|l|}{ Surface texture } \\
\hline$A$ & $60(100.0)$ & $58(96.66)$ & $55(91.66)$ & $50(83.33)$ \\
\hline $\mathrm{B}$ & $0(0.0)$ & $2(3.33)$ & $4(6.66)$ & $6(10.00)$ \\
\hline $\mathrm{C}$ & $0(0.0)$ & $0(0.0)$ & $1(1.66)$ & $3(5.00)$ \\
\hline $\mathrm{D}$ & $0(0.0)$ & $0(0.0)$ & $0(0.0)$ & $1(1.66)$ \\
\hline \multicolumn{5}{|l|}{ Color match } \\
\hline A & $60(100.00)$ & $59(98.33)$ & $56(93.33)$ & $53(88.33)$ \\
\hline B & $0(0.0)$ & $1(1.66)$ & $4(6.66)$ & $6(10.00)$ \\
\hline$C$ & $0(0.0)$ & $0(0.0)$ & $0(0.0)$ & $1(1.66)$ \\
\hline $\mathrm{D}$ & $0(0.0)$ & $0(0.0)$ & $0(0.0)$ & $0(0.0)$ \\
\hline \multicolumn{5}{|c|}{ Marginal adaptation } \\
\hline A & $60(100.00)$ & $58(96.66)$ & $54(90.00)$ & $47(78.33)$ \\
\hline B & $0(0.0)$ & $2(3.33)$ & $5(8.33)$ & $7(11.66)$ \\
\hline C & $0(0.0)$ & $0(0.0)$ & $1(1.66)$ & $3(5.00)$ \\
\hline $\mathrm{D}$ & $0(0.0)$ & $0(0.0)$ & $0(0.0)$ & $3(5.00)$ \\
\hline \multicolumn{5}{|c|}{ Marginal discoloration } \\
\hline A & $60(100.00)$ & $58(96.66)$ & $54(90.00)$ & $47(78.33)$ \\
\hline B & $0(0.0)$ & $2(3.33)$ & $5(8.33)$ & $7(11.66)$ \\
\hline C & $0(0.0)$ & $0(0.0)$ & $1(1.66)$ & $3(5.00)$ \\
\hline $\mathrm{D}$ & $0(0.0)$ & $0(0.0)$ & $0(0.0)$ & $3(5.00)$ \\
\hline \multicolumn{5}{|c|}{ Restoration integrity } \\
\hline$A$ & $60(100.00)$ & $60(100.00)$ & $59(98.33)$ & $57(95.00)$ \\
\hline B & $0(0.0)$ & $0(0.0)$ & $1(1.66)$ & $2(3.33)$ \\
\hline $\mathrm{C}$ & $0(0.0)$ & $0(0.0)$ & $0(0.0)$ & $1(1.66)$ \\
\hline $\mathrm{D}$ & $0(0.0)$ & $0(0.0)$ & $0(0.0)$ & $0(0.0)$ \\
\hline \multicolumn{5}{|l|}{ Tooth integrity } \\
\hline A & $60(100.00)$ & $60(100.00)$ & $58(96.66)$ & $55(91.66)$ \\
\hline$B$ & $0(0.0)$ & $0(0.0)$ & $2(3.33)$ & $2(3.33)$ \\
\hline C & $0(0.0)$ & $0(0.0)$ & $0(0.0)$ & $1(1.66)$ \\
\hline $\mathrm{D}$ & $0(0.0)$ & $0(0.0)$ & $0(0.0)$ & $2(3.33)$ \\
\hline \multicolumn{5}{|l|}{ Sensitivity } \\
\hline$A$ & $55(91.66)$ & $60(100.00)$ & $60(100.00)$ & $56(93.33)$ \\
\hline B & $5(8.33)$ & $0(0.0)$ & $0(0.0)$ & $3(5.00)$ \\
\hline C & $0(0.0)$ & $0(0.0)$ & $0(0.0)$ & $1(1.66)$ \\
\hline $\mathrm{D}$ & $0(0.0)$ & $0(0.0)$ & $0(0.0)$ & $0(0.0)$ \\
\hline \multicolumn{5}{|l|}{ Patient satisfaction } \\
\hline$A$ & $60(100.00)$ & $60(100.00)$ & $56(93.33)$ & $49(81.66)$ \\
\hline B & $0(0.0)$ & $0(0.0)$ & $3(5.00)$ & $7(11.66)$ \\
\hline C & $0(0.0)$ & $0(0.0)$ & $1(1.66)$ & $3(5.00)$ \\
\hline $\mathrm{D}$ & $0(0.0)$ & $0(0.0)$ & $0(0.0)$ & $1(1.66)$ \\
\hline
\end{tabular}

Abbreviations: A, Alpha; B, Bravo; C, Charlie; D: Delta.

polymerization facilitates the improvement of conversion of reactable $\mathrm{C}=\mathrm{C}$ double bonds and a reduction of residual internal stresses, yielding better mechanical properties. ${ }^{18,24}$

Marginal discoloration and marginal disintegration were detected in three cases respectively at the end of the 9-year follow-up. It was hypothesized that these phenomena were interrelated and that both would deteriorate with time. These results could be related to the resin composite luting cement, which considered as the weakest point for these kinds of restorations. ${ }^{11,18,19,22,25}$ Because adhesive inlays and 
onlays are inserted into the cavities with e resin cement, the luting gap is always susceptible to increased wear, as the mechanical properties of the cement are inferior, compared with the highly wear-resistant, postcured polymeric restorations. Loss of marginal adaptation is often due to polymerization shrinkage or removal of cement with instruments from the margins. The extent of microleakage depends on the extension of the margins on enamel or dentin. ${ }^{26}$ This happens because even though polymerization shrinkage is the same, regardless of the location of margins, microleakage is greater when the cementation is made on dentine. This problem is supposedly related to dentin dehydration and the compression of the frail collagen network exposed by dentin etching during restoration insertion, while the hybrid layer structure is not stabilized by cured bonding resin. Besides, the cement at the margins is exposed to corrosion or degradation due to the activity of enzymes, changes in $\mathrm{pH}$ that occur always in the mouth, and also due to mechanical detachment. Also, the type of resin cement (light-cured or dual-cured) combined with the time of polymerization may affect this microleakage. All these factors were responsible for the development of marginal gaps. The pigmentation molecules are apart to stay and absorb at disintegrated margins caused by microfracture of wear of resin cement. These disintegrated areas remain and will expand with time. ${ }^{4,27}$ Thus, this marginal disintegration will continue to exist or to increase along with the marginal discoloration. Discoloration of the margins also can be attributed to staining with pigments from food, coffee, and beverages, as well as smoking. Generally, the wear resistance of luting cement has been regarded with skepticism, regardless of the inlay/onlay material. ${ }^{4,19,28-32}$

Several clinical studies on indirect composite resins inlays and onlays reported no failure or low failure rates. ${ }^{11,18,19,21,22}$ In a 12-year study of clinical performance of one-two and multisurface composite resin inlays on premolars and molars, the failure rate was only $12 \% .{ }^{19}$ In another study, after 3 years of clinical service, $93 \%$ of the composite inlays in posterior teeth showed satisfactory results. ${ }^{18}$ Dukic et $\mathrm{al}^{21}$ reached a $70.7 \%$ success rate 36 months after placement and concluded that indirect composite resin restorations represent a good choice for the therapy of severely damaged teeth. Leirskar quotes 95\% clinically successful results for three kinds of indirect resin composite inlays/onlays after 4 to 6 years. ${ }^{33}$ Thordrup ${ }^{34}$ shows that after 10 years around $80 \%$ of the inlays placed were in function. Tunac et $\mathrm{al}^{35}$ evaluated the 2-year clinical performance of computer-aided design/computer-aided manufacturing resin composite inlay restorations in comparison with direct resin composite restorations. They concluded that all restorations were ideal or clinically acceptable in class II cavities.

\section{Conclusion}

This clinical survey was evaluated the clinical performance of 60 indirect polymer composite (Gradia) inlays and onlays placed in 32 patients for 9 years by using modified USPHS criteria. The success rate of the restorations at 9 -year follow-up was $85 \%$ and the failure rate was $15 \%$.
An Alpha score was given to $15 \%$ of the restorations, a Bravo score was given to $50 \%$, a Charlie score was assigned to $20 \%$, and a D score was given to $15 \%$ of the restorations. In conclusion, this kind of restoration seems clinically acceptable as a conservative and esthetic method for molar and premolar restoration.

\section{Funding}

None.

\section{Conflict of Interest}

None declared.

\section{References}

1 Molin M, Karlsson S. A 3-year clinical follow-up study of a ceramic (Optec) inlay system. Acta Odontol Scand 1996; 54(3):145-149

2 Hayashi M, Wilson NHF, Yeung CA, Worthington HV. Systematic review of ceramic inlays. Clin Oral Investig 2003;7(1):8-19

3 Messer PF, Piddock V, Lloyd CH. The strength of dental ceramics. J Dent 1991;19(1):51-55

4 Galiatsatos AA, Bergou D. Six-year clinical evaluation of ceramic inlays and onlays. Quintessence Int 2008;39(5):407-412

5 Magne P, Belser UC, Porcelain versus composite inlays/onlays: effects of mechanical loads on stress distribution, adhesion, and crown flexure. J Periodont Rest Dent2003;;23(6):543-555

6 Fron Chabouis H, Smail Faugeron V, Attal JP. Clinical efficacy of composite versus ceramic inlays and onlays: a systematic review. Dent Mater 2013;29(12):1209-1218

7 Fonseca RB, Correr-Sobrinho L, Fernandes-Neto AJ, Quagliatto PS, Soares CJ. The influence of the cavity preparation design on marginal accuracy of laboratory-processed resin composite restorations. Clin Oral Investig 2008;12(1):53-59

8 Leinfelder KF. New developments in resin restorative systems. J Am Dent Assoc 1997;128(5):573-581

9 Chalifoux PR. Treatment considerations for posterior laboratory-fabricated composite resin restorations. Pract Periodontics Aesthet Dent 1998;10(8):969-978, quiz 980

10 Nandini S. Indirect resin composites. J Conserv Dent 2010; 13(4):184-194

11 Fasbinder DJ, Dennison JB, Heys DR, Lampe K. The clinical performance of CAD/CAM-generated composite inlays. J Am Dent Assoc 2005;136(12):1714-1723

12 Gracis S, Thompson VP, Ferencz JL, Silva NR, Bonfante EA. A new classification system for all-ceramic and ceramic-like restorative materials. Int J Prosthodont 2015;28(3):227-235

13 Aslan YU, Coskun E, Ozkan Y, Dard M. Clinical evaluation of three types of CAD-CAM inlay/onlay materials after 1-year clinical follow-up. Eur J Prosthodont Restor Dent 2019;27(3):131-140

14 Ryge G, Snyder M. Evaluating the clinical quality of restorations. J Am Dent Assoc 1973;87(2):369-377

15 Cvar JF, Ryge G. Reprint of criteria for the clinical evaluation of dental restorative materials. 1971. Clin Oral Investig 2005;9(4):215-232

16 Freilich MA, Goldberg AJ, Gilpatrick RO, Simonsen RJ. Direct and indirect evaluation of posterior composite restorations at three years. Dent Mater 1992;8(1):60-64 
17 Cvar JF, Ryge G, Criteria for the clinical evaluation of dental restorative materials. USPHS Publication \#790-2441971; San Francisco: US Government Printing Office Doi: 10.1007/ s00784-005-0018-z

18 Manhart J, Neuerer P, Scheibenbogen-Fuchsbrunner A, Hickel R. Three-year clinical evaluation of direct and indirect composite restorations in posterior teeth. J Prosthet Dent 2000;84(3):289-296

19 Derchi G, Marchio V, Borgia V, Özcan M, Giuca MR, Barone A. Twelve-year longitudinal clinical evaluation of bonded indirect composite resin inlays. Quintessence Int 2019;50(6):448-454

20 Goldberg AJ, Rydinge E, Santucci EA, Racz WB. Clinical evaluation methods for posterior composite restorations. J Dent Res 1984;63(12):1387-1391

21 Dukic W, Dukic OL, Milardovic S, Delija B. Clinical evaluation of indirect composite restorations at baseline and 36 months after placement. Oper Dent 2010;35(2):156-164

22 Ozsoy A, Kusdemir M, Ozturk-Bozlurt F. Toz Akalin T, Ozcan M. Clinical performance of indirect composite onlays and overlays: 2-year follow-up. J Adhes Sci Technol 2016;30(16):1808-1818

23 Stawarczyk B, Egli R, Roos M, Ozcan M, Hämmerle CH. The impact of in vitro aging on the mechanical and optical properties of indirect veneering composite resins. J Prosthet Dent 2011;106(6):386-398

24 Tanoue N, Matsumura H, Atsuta M. Comparative evaluation of secondary heat treatment and a high intensity light source for the improvement of properties of prosthetic composites. J Oral Rehabil 2000;27(4):288-293

25 Al-Haj Husain N, Özcan M, Molinero-Mourelle P, Joda T. Clinical performance of partial and full-coverage fixed dental restorations fabricated from hybrid polymer and ceramic CAD-CAM materials: a systematic review and meta-analysis. J Clin Med 2020;9(7):2107
26 Panchal N, Mehta SB, Banerji S, Millar BJ. Aesthetic resin onlay restorations: 'rationale and methods' Dent Update 2011;38(8):535-536, 539, 542-544

27 Feilzer AJ, De Gee AJ, Davidson CL. Increased wall-to-wall curing contraction in thin bonded resin layers. J Dent Res 1989;68(1):48-50

28 Kawai K, Isenberg BP, Leinfelder KF. Effect of gap dimension on composite resin cement wear. Quintessence Int 1994;25(1):53-58

29 Lüescher B, Lutz F, McDermott T, Mühlemann HR. The prevention of microleakage and achievement of optimal marginal adaptation. J Prev Dent 1977;4(2):16-21

30 Qvist V, Qvist J. Replica patterns on composite restorations performed in vivo with different acid-etch restorative procedures. Scand J Dent Res 1985;93(4):360-370

31 De Munck J, Van Meerbeek B, Yoshida Y, et al. Four-year water degradation of total-etch adhesives bonded to dentin. J Dent Res 2003;82(2):136-140

32 Frankenberger $R$, Strobel WO, Lohbauer U, Krämer N, Petschelt A. The effect of six years of water storage on resin composite bonding to human dentin. J Biomed Mater Res B Appl Biomater 2004;69(1):25-32

33 Leirskar J, Nordbø H, Thoresen NR, Henaug T, von der Fehr FR. A four to six years follow-up of indirect resin composite inlays/onlays. Acta Odontol Scand 2003;61(4):247-251

34 Thordrup M, Isidor F, Hörsted-Bindslev P. A prospective clinical study of indirect and direct composite and ceramic inlays: ten-year results. Quintessence Int 2006;37(2):139-144

35 Tunac AT, Celik EU, Yasa B. Two-year performance of CAD/CAM fabricated resin composite inlay restorations: a randomized controlled clinical trial. J Esthet Restor Dent 2019;31(6):627-638 